\title{
LA CASA DE los conejos de LaURa Alcoba Y LA (RE)CONSTRUCCIÓN DE LA IDENTIDAD EN EL MARCO DEL DOLOROSO lEGADO DEL TERRORISMO DE Estado EN ARGENTINA*
}

\author{
Diana Pifano** \\ Dalhousie University \\ María Soledad Paz-Mackay*** \\ St. Francis Xavier University
}

\section{Resumen}

Recientemente se ha visto una multitud de novelas que exploran la última dictadura militar argentina desde la perspectiva de la segunda generación: los hijos de militantes de izquierda, víctimas del terror estatal. Entre ellas, La casa de los conejos de Laura Alcoba narra la experiencia de la vida clandestina y el trauma de la pérdida familiar resultante del exilio forzado. Este trabajo describe la dificultad de recontar aquel pasado violento y explora la voz narrativa infantil como estrategia narrativa para circunvalarlo. Finalmente describe como el proceso auto-reflexivo de narrativización abre la puerta a la (re) construcción de una identidad fracturada.

Palabras clave: Literatura argentina; Última dictadura militar; Hijos de desaparecidos; Memoria; Identidad.

Recibido: 29 de febrero de 2016

Aprobado: 6 de abril de 2016

*Este artículo hace parte de un proyecto sobre la memoria, la identidad y el humor en la producción cultural de los hijos de los desaparecidos en Argentina, subvencionado por el Social Sciences Research Council de Canadá.

**Profesora Asistente en el Departamento de Español y Estudios Latinoamericanos de Dalhousie University. Se especializa en el estudio del humor en la literatura latinoamericana contemporánea.

Dirección electrónica: Diana.Pifano@dal.ca

***Profesora Asistente en el Departamento de Lenguas Modernas de la Universidad St. Francis Xavier, en Antigonish, Nova Scotia (Canadá). Su área de especialización es la literatura y cine latinoamericano contemporáneo, con un foco especial en el Cono Sur.

Dirección electrónica: mpaz@stfx.ca 


\title{
Laura Alcoba's La casa de los conejos. (Re)constructing Identity in the Wake of Argentina's Painful Legacy of State Terrorism
}

\begin{abstract}
Recent years have seen a growing number of novels that explore Argentina's last military dictatorship from the point of view of the second generation, the children of the victims of state terrorism. Among them, La casa de los conejos by Laura Alcoba describes clandestine life, and the loss and trauma that accompany forced exile. This paper describes the difficulty involved in retelling that violent past, and how the narrative voice of the child protagonist functions as a tool to circumvent such obstacles. Finally, it examines how the self-reflective process of narrating these experiences is the basis for (re)constructing a fractured identity.
\end{abstract}

Keywords: Argentinean Literature; Military Dictatorship; Children of the Disappeared; Memory; Identity.

Cómo citar este artículo

APA: Pifano, D. \& Paz-Mackay, S. (2016). La casa de los conejos de Laura Alcoba y la (re) construcción de la identidad en el marco del doloroso legado del terrorismo de Estado en Argentina. Poligramas, No. 42, junio., pp.: 127-156

MLA: Pifano, Diana y Paz-Mackay, Soledad. "La casa de los conejos de Laura Alcoba y la (re)construcción de la identidad en el marco del doloroso legado del terrorismo de Estado en Argentina". Poligramas 42 (2016): pp. 127-156 Print.

Chicago: Pifano, Diana y Paz-Mackay, Soledad. 2016. La casa de los conejos de Laura Alcoba y la (re)construcción de la identidad en el marco del doloroso legado del terrorismo de Estado en Argentina. Poligramas 42 (junio): pp. 127-156 
Durante las últimas décadas han surgido numerosas narrativas que trabajan el doloroso legado de la última dictadura militar argentina y negocian su interpretación contemporánea. Este artículo explora La casa de los conejos de Laura Alcoba, una novela protagonizada y narrada por una niña que es testigo observador de la vida clandestina de su madre, quien en los primeros días del régimen estuvo a cargo de una imprenta del grupo Montoneros. ${ }^{1}$ Ella recuenta los efectos devastadores de esa experiencia y la pérdida familiar que sufre a manos del régimen. Según Gabriel Gatti, esta narración debe superar lo que ha llamado una catástrofe del sentido; una condición a partir de la cual ningún lenguaje o sistema de referencia logra describir plenamente el trauma causado por los crímenes de lesa humanidad perpetrados por las dictaduras del cono sur durante el siglo XX, en especial la detención-desaparición forzada. ${ }^{2}$ Este trabajo explora las estrategias narrativas alternativas empleadas por Alcoba para circunvalar aquellos aspectos del pasado que resultan indescriptibles y dar sentido a las relaciones afectivas de la protagonista, las cuales se deben (re)construir a la luz de la pérdida de sus seres queridos. Se analiza específicamente la voz infantil como estrategia que media y enuncia la tragedia, y que esboza la construcción de una identidad in absentia.

En nuestro análisis proponemos que la protagonista narra las vivencias traumáticas de su niñez en un intento de reconstruir su identidad individual y familiar. Al pasar a la clandestinidad, con tan solo 7 años de edad, ella debe dejar atrás la rutina y los afectos, y aprender a callar para proteger a sus seres queridos. Desde su presente de adulta, la protagonista comienza la recomposición de su identidad fracturada con el acto mismo de la narración. Luego de 32 años de silencio, al contar su historia vuelve a nombrar a sus seres queridos, y así a nombrarse a sí misma. El regreso a los eventos que comenzaron en 1975 y terminaron en su exilio es un ejercicio de memoria que al mismo tiempo se convierte en una asunción de identidad.

Esta investigación se dividirá en tres partes. En primer lugar vamos a contextualizar la novela de Alcoba dentro del marco de la literatura argentina sobre la última dictadura militar y, de manera más específica, como representante de un movimiento reciente que explora los horrores 
del pasado desde una perspectiva reflexiva. Señalaremos aquellas cualidades comunes que caracterizan al movimiento y los elementos que la novela de Alcoba comparte con sus coetáneos. En segundo lugar vamos a analizar varios aspectos formales de La casa de los conejos en torno al planteamiento de Gatti respecto a la dificultad de narrar el trauma que resultó del terrorismo de Estado. En especial prestaremos atención a la voz narrativa infantil que sirve como conducto para enunciar la tragedia. Por último, vamos a discutir la construcción de la identidad como un proceso auto-reflexivo en el cual la autora vuelve a asumir una identidad construida en base a los recuerdos de la clandestinidad con el propósito de rendir homenaje a los seres queridos del pasado.

Antes de comenzar en pleno, cabe aclarar que La casa de los conejos es una autoficción, modalidad descrita por Serge Doubrovsky al hablar de su novela Fils, que reúne la ficción y la autobiografía. Es decir que es una obra donde autor, personaje y narrador tienen la misma identidad. En el caso que se estudia, Alcoba entrecruza la ficción con sus recuerdos de la casa ubicada en La Plata, que el 24 de noviembre de 1976, poco después de su exilio, fue atacada por las fuerzas armadas del gobierno. En ese enfrentamiento murió Diana Teruggi, quien aparece en la novela como Didí. El cuerpo de su hija recién nacida, Clara Anahí, nunca se recuperó. Su familia cree que fue apropiada y aún la buscan.

\section{La literatura de los hijos de desparecidos}

En la producción cultural argentina del nuevo milenio se observa un grupo de novelas que exploran el trauma ocasionado por la violencia y los crímenes de lesa humanidad perpetrados durante la última dictadura militar con nuevas e interesantes perspectivas. Este corpus está compuesto en parte por una serie de autoficciones escritas por autores que son hijos de desaparecidos, y en igual medida, se compone de ficciones escritas por autores que, aunque vivieron la época y en algunos casos participaron en la militancia, no son descendientes de las víctimas del régimen. ${ }^{3}$ Este corpus se distingue debido a que se sitúa a una generación de la época histórica a la que refiere, y se distancia de las obras previas sobre el mismo tema en base a una separación temporal y cultural. Estas novelas ya no comparten la temática ni las estrategias 
narrativas asociadas a lo que se ha llamado la primera generación de textos sobre la dictadura, cuya intención primordial era sacar a la luz las prácticas de detención, tortura, desaparición y muerte desempeñadas por la Junta Militar y sus agentes. Estas, más bien, son obras posteriores que dan por sentado que sus lectores poseen conocimiento histórico sobre el régimen. Su intención es reflexiva y no informativa.

Sin embargo, para describir este corpus es necesario referir primero a aquellos textos anteriores que comparten el mismo eje temático. En primer lugar, es importante mencionar una categoría de literatura testimonial que da cuenta de la experiencia vivida por las víctimas directas del régimen. ${ }^{4}$ Sin embargo, la gran mayoría de los textos que exploran el tema de la dictadura militar son ficticios y, como consecuencia, la mayor parte de los trabajos académicos sobre el tema se centran en las ficciones producidas durante el régimen (1976-1983) y el período inmediatamente posterior. Al referirse a este grupo de novelas publicadas durante la dictadura militar, Beatriz Sarlo (1993) expresa que:

Ante la represión o la muerte, ante el fracaso y las ilusiones perdidas, los discursos narrativos pusieron en escena la perplejidad, según dos estrategias narrativas principales: la refutación de la mímesis como forma única de representación, por un lado; la fragmentación discursiva tanto de la subjetividad como de los hechos sociales, por el otro. (p.10)

Según lo explica la autora, la literatura aparece como un espacio reflexivo que posibilita la producción de un discurso interrogativo (p.10). Sarlo se basa en ejemplos de novelas como Nada, Nadie, Nunca de Juan José Saer o Hay cenizas en el viento de Carlos Dámaso Martínez, en las cuales la fragmentación de la narración se presenta como una estrategia para poner en evidencia la imposibilidad de la existencia de un solo punto de vista narrativo o de un solo discurso. En el mismo sentido se expresa Andrés Avellaneda cuando sostiene que "la literatura escrita durante el Proceso había adoptado como cuestión estética central la crisis de lo verosímil y de la representación realista" (1995, p.27). Según el autor, esta literatura apela "a narrar el funcionamiento mismo del relato sobre lo real, ya sea destacando los grados 'segundos' 
de la alusión y la alegoría, o el grado 'cero' de la hiperliterariedad" (1997, p.142). Estas tendencias se repiten en la mayoría de las novelas publicadas durante la dictadura en las cuales se evidencia que la técnica utilizada por los escritores del momento para referirse a la etapa de violencia política era la ruptura con el modelo de representación realista y la utilización de técnicas vanguardistas, como la fragmentación del relato.

Con el regreso de la democracia en 1983 y, especialmente a partir de 1985 con la publicación de La novela de Perón de Tomás Eloy Martínez, se abre un período en el cual, el tema de la violencia y radicalización política vivida durante la dictadura va a pasar a un segundo plano para dar lugar a novelas con temas históricos relacionados a la formación de la nación en el siglo XIX y al primer gobierno peronista en el siglo XX. En relación a las novelas de dictadura, Fernando Reati (1992, p.170) opina que ante la ausencia de una versión oficial ya cristalizada, la novela argentina ingresa en una tercera opción: la de ofrecerse ella misma como una posible historia de los hechos, a través de la memoria y de la puesta en duda de toda versión definitiva. El autor considera a la novela como creadora de nuevos sentidos relativos a la última dictadura militar desde el presente en democracia. ${ }^{5}$

El año 1995 marca un hito importante en el discurso social de la posdictadura con la aparición de las confesiones de militares involucrados en las torturas y el reconocimiento público de la participación militar en los delitos cometidos durante el "Proceso de Reorganización Nacional", todo lo cual produce un cambio transcendente en cuanto a la forma de entender la responsabilidad por los horrores acontecidos durante el régimen. ${ }^{6}$ María Teresa Gramuglio reflexiona sobre las novelas de dictadura y las que les siguieron, e insiste en que la investigación de la CONADEP y el Juicio a la Juntas agregaron "un giro decisivo en el universo de los discursos" (2002, p.10) y, además, modificaron las condiciones discursivas para aquellas novelas que volvían sobre los núcleos más duros de la dictadura. Al analizar la novela Villa de Luis Gusmán, Gramuglio (2002) opina que

[t]rabaja... con procedimientos propios de la representación realista: la articulación de la historia sobre el orden temporal-causal; las 
notaciones precisas de nombres, tiempos y lugares; la estabilidad del punto de vista narrativo; el despojamiento de los recursos retóricos que marcan el lenguaje poético.... Construye así un verosímil estricto para una historia inverosímil. (p.12)

Miguel Dalmaroni (2003) se expresa en similar sentido cuando refiere a un grupo de novelas publicadas a partir de 1995 que tematizan los conflictos de la última dictadura militar. Explica que lejos de la oblicuidad, de la fragmentación o del ciframiento alegórico, algunas novelas procuran abrir la posibilidad de narrar refiriendo por completo, y de modo directo, a los sucesos más atroces e inenarrables; no obstante parece necesario anotar que tanto los registros de los narradores como las construcciones de trama, por más que remitan a cierto impulso realista o literal respecto de lo representado, tienen poco de "prosa diáfana" o de relato lineal (2003, p.34).

En esta investigación nos concierne un texto representante de aquello que se podría considerar como la segunda generación de novelas sobre la última dictadura militar: un grupo de textos que comienza a vislumbrarse a finales del siglo XX y cobra fuerza después del 2003. Este corpus da por sentado que sus lectores poseen un conocimiento histórico de lo acontecido durante el régimen y los años en que se tramitó el retorno a la democracia. Son textos que se ubican en un momento posterior al régimen militar y a los grandes juicios, cuyos autores tienen vínculos estrechos con los movimientos de defensa de los derechos humanos. ${ }^{7}$ Sin embargo, con excepción de ¿Quién te crees que sos? (Urondo Raboy, 2013) que constituye un caso especial en la literatura escrita por hijos de desaparecidos, estas novelas no ahondan las implicaciones legales de los abusos del régimen. ${ }^{8}$ La gran mayoría de ellos, incluyendo La casa de los conejos, aborda una temática emotiva y personal enfocada en la familia y la participación individual en los grupos de militantes de izquierda.

Como conjunto se puede decir que este corpus, que continúa creciendo, es el producto de un cambio fundamental en el diálogo sobre la dictadura y la memoria que ocurrió en el año 2003, cuando Néstor Kirchner expresó, en su discurso inaugural, su conexión emotiva para con las víctimas: "Formo parte de una generación diezmada, castigada 
con dolorosas ausencias; me sumé a las luchas políticas creyendo en valores y convicciones a las que no pienso dejar en la puerta de entrada de la Casa Rosada". Este acto reanudó un diálogo que durante muchos años había estado marginado en el ámbito de la política. Durante su gobierno, Kirchner apoyó a sobrevivientes, familiares de las víctimas y asociaciones de defensa de los derechos humanos. Eliminó los retratos de los militares implicados en los abusos del régimen de los espacios gubernamentales, expropió la Escuela de Mecánica de la Armada, ESMA, donde había existido uno de los más grandes centros de detención y tortura, y la convirtió en un espacio para la memoria. Creó una nueva circunstancia socio-política que dio ímpetu a una nueva exploración del tema y nutrió una producción cultural que continúa examinando la dictadura y sus efectos. Así, a partir del 2003 se ve un incremento en la producción literaria, cinemática, y artística en general, y la novela en estudio se puede identificar con este movimiento. Inclusive en el prólogo, Laura Alcoba expresa que el deseo de contar esta historia corresponde a un viaje que hizo a Argentina a finales del 2003.

En muchos casos, incluyendo La casa de los conejos, las novelas escritas por hijos de desaparecidos se centran en las experiencias de la segunda generación, que ya es adulta y busca dar sentido a aquello que no pudo entender por su temprana edad, o de lo cual simplemente no tuvo conciencia. Jordana Blejmar y Natalia Fortuny (2013) describen varias cualidades comunes a la producción cultural de los hijos de desaparecidos. Entre ellas, las autoras hablan de cómo se plantea la fusión de lo autobiográfico y lo ficticio de una manera que no se había visto en la literatura de décadas anteriores, cuando se producían reproducciones realistas de los eventos o interpretaciones alegóricas de ellos, por separado (p. 3). Blejmar y Fortuny explican que, para esta segunda generación, los modelos anteriores ya no bastan, y ellos prefieren alternar entre la exposición y el ocultamiento de su identidad y sus experiencias $(2013$, p.3). En el caso de La casa de los conejos, Laura, la niña protagonista de esta novela, presenta una trama que es ficticia pero se basa en la realidad, y deja al lector preguntándose dónde queda el límite de lo real. 
Otra cualidad común a este corpus es que a menudo sus autores abordan el pasado desde la mirada infantil. Blejmar y Fortuny refieren a esta técnica usando términos como "playful memory" y "child-like gaze" (2013, p.4). Pues bien, en el texto que analizamos, Alcoba se vale de la voz narrativa infantil, encubierta de la vaguedad que poseen los recuerdos lejanos, para presentar un universo narrativo complejo en el cual la violencia se esconde a flor de piel. Sin embargo es importante mencionar que La casa de los conejos es sólo una de las obras que se vale de esta técnica. Otro relato similar es Pequeños combatientes de Raquel Robles. Sin embargo, mientras que Alcoba se centra en los eventos previos a la ruptura del lazo familiar, la novela de Robles tiene lugar después de la desaparición de los padres de la niña protagonista y se enfoca en la manera como ella se adapta a su nueva situación, a la luz de la ausencia de sus padres. ${ }^{9}$

Un aspecto particular a la novela de Alcoba es su prólogo. Este apartado es de interés porque expone una reflexión a posteriori que enmarca el resto del relato. Formulado a manera de epístola dirigida a Diana Teruggi, el prólogo se desarrolla en un momento narrativo en que Laura es adulta y comenta sobre los eventos del pasado con la intención de rendir homenaje tanto a los muertos como los vivos. No cabe duda de que esta voz narrativa adulta es un alter ego de Alcoba, que hace explícito su deseo, común entre los hijos de desaparecidos, de recordar o (re)construir una memoria de lo sufrido que les permita negociar el pasado y encarar su identidad en el marco de la ausencia de sus seres queridos. Aunque reconocemos que esta narración posee una cualidad testimonial y que Laura Alcoba, al igual que el resto de los niños que estuvieron expuestos a la violencia del régimen, es una víctima de él, postulamos que el elemento central de esta novela es que realiza esta reflexión sobre el pasado. La autora toma la palabra 32 años después de los eventos narrados para intentar construir su identidad en torno a la experiencia vivida y la ruptura de las relaciones afectivas.

\section{Catástrofes y dificultades}

Este tipo de narración corresponde a lo que Gabriel Gatti denomina "narrativas de la ausencia de sentido", es decir aquellas que son 
"construidas en y sobre la catástrofe que provoca la desaparición forzada" (2001, p.112). Es necesario precisar que la trama de la novela de Alcoba no incluye una detención-desaparición, ni tampoco los padres de la autora fueron víctimas de esta práctica, sin embargo es algo que está presente en el universo narrativo que ella describe y permea toda discusión sobre el terror estatal y los crímenes de lesa humanidad ocurridos durante el régimen. Es imposible desligar la violencia de la dictadura de las prácticas de detención-desaparición. La siguiente cita aparece en las primeras páginas de la novela y sirve para exponer la situación de la protagonista:

Hemos tenido que dejar nuestro departamento, dice, porque desde ahora los Montoneros deberán esconderse. Es necesario, ciertas personas se han vuelto muy peligrosas: son los miembros de los comandos de las AAA, la Alianza Anticomunista Argentina, que "levantan" a los militantes como mis padres y los matan o los hacen desaparecer. Por eso debemos refugiarnos, escondernos, y también resistir. Mi madre me explica que eso se llama "pasar a la clandestinidad". (Alcoba, 2010, pg. 9)

Así, es posible extender las propuestas de Gatti a una trama que no incluye detención-desapariciones pero sí la amenaza de ellas y eventos violentos de otra naturaleza. La novela describe no sólo el estado de terror en el que operan los personajes sino también la huida y el exilio forzado de la protagonista y su madre, las cuales implican la ruptura definitiva de vínculos familiares y los lazos afectivos que Laura había formado durante su estadía en la casa. Es importante notar que al huir Laura deja atrás a su padre, su familia materna, su patria, su idioma nativo, y a Didí y Cacho, compañeros de la vida clandestina, por quienes sentía un gran cariño. En lo que sigue, discutiremos cómo Laura desarrolla un lazo pseudo-filial con Didí durante su estadía en la casa de los conejos. Para la niña que tiene apenas 7 años, la ruptura es total y las consecuencias complejas. Tanto así que el trauma de estas experiencias motiva a la autora a narrar su historia, tres décadas después, cuando encuentra un ambiente propicio.

La clasificación que realiza Gatti (2001) de las "narrativas de la ausencia de sentido" forma parte una propuesta mucho más amplia, 
desarrollada en varios trabajos, donde el sociólogo uruguayo ha descrito las consecuencias socio-culturales de la detención-desaparición y las representaciones artísticas relacionadas con ella. ${ }^{10}$ De acuerdo a él, la detención-desaparición es un evento permanente que priva a su víctima de su ciudadanía, disocia a su cuerpo de su identidad y devasta tanto a la víctima como a sus seres queridos. Dicha catástrofe anula todo sistema de referencia, de manera que resulta imposible que el lenguaje verdaderamente describa su condición (2001, p.32). Según Gatti:

La catástrofe es la quiebra de las relaciones convencionales entre la realidad social y el lenguaje que casa con ella para analizarla y para vivirla; aparece cuando esta quiebra se consolida y esa consolidación constituye espacios sociales que, aunque con dificultades para la representación se representan y aunque con problemas para la construcción de identidad, ésta se hace. (2001, p.38)

Es posible ubicar el argumento de Gatti dentro del recuento histórico de las tendencias de la literatura argentina que hemos realizado en páginas anteriores. ${ }^{11}$ Hemos mencionado en varios momentos la (im) posibilidad de realizar una representación realista de los horrores de la época - la refutación de la mímesis que describe Sarlo, y el intento fallido por crear una prosa realista que menciona Dalmaroni - y las diferentes aproximaciones que adoptaron los escritores en sus respectivos contextos, como la fragmentación del discurso en obras escritas durante el régimen y algunos años después, el haber optado por una temática histórica que refería a la formación de la nación o al primer gobierno peronista. Si bien en los años que siguieron al fin del régimen no existía un relato oficial o un marco teórico que permitiera reflexionar sobre los efectos de las prácticas represivas, 40 años después poseemos una visión mucho más amplia que nos permite abordar la escritura de la generación que hereda ese legado. Los postulados de Gatti están basados en un estudio sociológico de la detención-desaparición y sus consecuencias, pero se extienden a la producción cultural, e ilustran precisamente esa visión contemporánea, distanciada y reflexiva. Con esto en mente, nuestro estudio parte de la premisa, basada en estos postulados, de que esta novela se centra alrededor de un tema que se resiste a ser representado por completo. 
En base a esto planteamos que al mantener una perspectiva narrativa infantil a lo largo de la descripción de los eventos del pasado, La casa de los conejos circunvala y negocia los momentos determinantes de la tragedia y sus detalles. A nuestro parecer esta estrategia narrativa refleja la dificultad descrita por Gatti, ya que la voz infantil es capaz de suavizar aquellas porciones de las narraciones que de recontarse en detalle, resultarían violentas o difíciles. Alcoba parte de la incomodidad y la imposibilidad de narrar la totalidad de las experiencias de Laura. Mientras que algunos elementos de su vida clandestina resultan cotidianos y hasta naturales, Laura no trata de darle sentido a aquellos elementos que reflejan la violencia de la época o el peligro que los acecha. Por el contrario, la autora desplaza el contenido violento o difícil de la narración a objetos y situaciones cotidianas. Esta técnica está en línea también con los planteamientos de Blejmar y Fortuny, quienes describen esta evasión como parte del juego hecho por la perspectiva infantil (2013, pg. 4). En vez de representar directamente el terror de la época, Alcoba elige estrategias representativas complejas centradas alrededor de su protagonista. El siguiente es un ejemplo de cómo se le da un enfoque infantil a la narración del ambiente en que se desarrolla la acción en la novela:

Vamos a casa de Carlitos, mi abuela y yo [...]. Nos detenemos varias veces por el camino, para ver si alguien nos sigue. No es más que una cuestión de rutina.

Casi siempre, soy yo la que se vuelve a mirar hacia atrás. Resulta más natural que un niño pare, dé media vuelta y desande sus propios pasos; en un adulto, en cambio, este comportamiento podría considerarse sospechoso, signo de una inquietud que nos pondría en peligro de llamar la atención. Por mi parte, aprendí a disimular estos actos de prudencia bajo la apariencia de un juego. (Alcoba, 2010, p.17)

De momento, este ejemplo refleja cómo la voz narrativa infantil funciona como una estrategia narrativa que permite superar la catástrofe del sentido. Volveremos sobre ello en la porción de estudio dedicada al análisis. 
Es necesario discutir cómo la reflexión que realiza Alcoba a través de esta novela constituye una formulación de una identidad específica, la cual a pesar de tener raíces comunes entre los integrantes de una generación, entre miembros de asociaciones de defensa de los derechos humanos y entre un número creciente de autores, no puede resumirse o simplificarse. Una de las bases de las investigaciones de Gatti es que el campo del detenido-desaparecido, sus agentes, instituciones, movimientos sociales, y producciones artísticas y culturales se centran alrededor de la temática de la identidad. La novela en cuestión se desarrolla en un ámbito devastado por la violencia del régimen, donde uno de los elementos determinantes en el proceso de formación de la identidad es la familia, o bien la ausencia de ciertos lazos afectivos. La protagonista vuelve al pasado para así insertarse en una identidad construida en ausencia. El recuento del paso a la clandestinidad es un intento de marcar su genealogía, de reconstruir los lazos emotivos que perdió a raíz de su exilio. Esa construcción identitaria se presenta como una herida abierta, como un dolor tangible pero indescriptible.

En ese sentido, la cuestión de la identidad es central en la producción cultural de los hijos de desaparecidos, ya que se relaciona directamente su legado familiar incompleto. Leonor Arfuch (2005) sostiene, en contra de las posiciones esencialistas, que la identidad no es un conjunto de cualidades predeterminadas. Su planteamiento es que la formulación de una identidad es un trabajo interminable, que existe como parte de la narrativización ficcional del ser individual o colectivo (p. 24). Ella nos dirige a preguntarnos cómo estos autores emplean los recursos del lenguaje, la historia y la cultura para devenir en un ser, y nos invita a reflexionar sobre cómo contar la propia historia es un proceso de construcción de la identidad "a partir de un ahora que cobra sentido en un pasado" (p. 27). La dimensión narrativa de la identidad resulta esencial por ser una puesta de sentido en la (re)construcción del pasado traumático derivado de la experiencia de la devastación. Esa resignificación desde su presente de adultos agrega nuevos sentidos a sus conflictivas experiencias personales durante la dictadura.

En línea con Arfuch, Hugo Vezzetti (2002) propone analizar no los acontecimientos ocurridos durante los años de violencia, sino 
las representaciones de ellos. En su estudio, "explora sobre todo imágenes, ideas y discursos, que son la materia misma de la memoria y la experiencia sociales" (p.14). Siguiendo estas pautas, planteamos que las ficciones protagonizadas por los hijos de desaparecidos, si bien son reconstrucciones de lazos afectivos íntimos, son relatos que (re) presentan la experiencia personal, cuya esencia es privada, en el marco de un proyecto artístico público y colectivo.

\section{Recuerdos infantiles de la vida clandestina}

Al narrar sus experiencias sobre la vida clandestina y el paso de la vida pública al anonimato, Laura intenta recomponer un pasado que no pudo apreciar del todo debido a su edad. Esta novela no representa el mundo de la infancia, ni es un relato infantil. Tampoco puede considerarse como bildungsroman debido a que no hay una verdadera evolución de la protagonista. Simplemente es un relato adulto mediado por una instancia narrativa infantil. Representa eventos violentos desde coordenadas de inocencia y así circunvala la angustia, el resguardo, el acecho de las fuerzas represivas, los secuestros, y una sensación de inminente derrota.

$\mathrm{Al}$ abordar el análisis debemos considerar que existen dos niveles de complejidad narrativa. El primero, relativo a la catástrofe del sentido descrita por Gatti; noción que se une al debate que inspiró Adorno al decir que no es posible hacer poesía después de Auschwitz. Gatti afirma que las palabras de Adorno son: "un recordatorio que reclamaba dirigir la reflexión a los límites del lenguaje (Auschwitz -o la figura del detenido-desaparecido- son indecibles, no porque no se deban decir sino porque no hay cómo decirlos) y a la necesidad de reflexionar en cómo superarlos (debe reflexionarse sobre cómo y con qué decir Auschwitz o la figura del detenido-desaparecido)" (2006, p. 35). ${ }^{12}$

En línea con ello, Alcoba se da la tarea de representar el día a día de los militantes en la clandestinidad, su vida cotidiana durante momentos de angustia extrema. El reto principal para la autora es encontrar formas de narrar los efectos directos del terrorismo de Estado sobre las personas que viven en la casa de los conejos. 
El segundo nivel de complejidad está ligado a la protagonista, que es la única voz narrativa. Se trata de una voz infantil que intenta narrar eventos clandestinos y sentimientos inefables. A pesar de que Laura sabe lo que ocurre y parece comprender la gravedad de su situación, la diégesis está limitada a la perspectiva de una niña de 7 años. El siguiente ejemplo demuestra está dualidad:

— ¿Viste esa mujer? La torturaron, pero no cantó. Le hicieron cosas horribles, sabés, cosas que no son para contarle a una nena como vos. Pero no abrió la boca. Aguantó todo sin decir una palabra.

Yo no insistí en saber en qué consistían esas "cosas". Yo también sé callarme, sí.

Y no hice más que imaginar.

E imaginé cosas que causan mucho dolor, mucho daño, con clavos oxidados o un montón de cuchillitos ahí adentro, bien profundo. Y a ella, que no había dicho nada. Entonces pensé, sin decirlo, que aquello era ser una mujer fuerte. Sí, eso era. (Alcoba, 2010, p.86)

Debemos tener en cuenta que el universo narrativo representa un estado aberrante de separación y aislamiento, donde los involucrados esconden su identidad, se convierten en forajidos, y viven en condiciones sumamente difíciles. A esto se suma que la autora ha optado por representarlos mediante una narradora ingenua con mucho menos conocimiento que el lector. Así, el pacto de verosimilitud que forma cada lector implica no sólo que él o ella aceptará que el texto intenta narrar eventos que se resisten a ser descritos, sino que él o ella tendrá un conocimiento histórico y entendimiento superior a la narradora, que le permitirá anticipar la narración. Es decir que la lectura no implica un proceso de descubrimiento para el lector, sino un repetido ajuste a las expectativas que haya creado en base a su conocimiento previo.

Una cualidad notable de esta voz infantil es que actúa como un mecanismo retórico inclusivo. Todo lector ha sido niño y puede identificarse con las emociones de Laura, pues son básicas para el ser humano: el miedo, la confusión, la vulnerabilidad, la vergüenza, el deseo de complacer a su madre y causar una impresión positiva en los mayores. Aun cuando el lector no se identifica con las circunstancias específicas de Laura, la instancia narrativa infantil promueve un pacto 
a nivel emocional que motiva al lector a convertirse en su aliado. Este proceso es independiente de la afiliación política de quien lee y de su bagaje cultural; aunque para el lector competente, quien se inserta en el diálogo actual sobre las trágicas consecuencias de la última dictadura militar argentina, se suma al duelo implícito en la memoria colectiva. A diferencia de las novelas presentadas por personajes adultos, los narradores infantiles crean un efecto de inclusión que influye en la interpretación de los eventos de la trama.

Un aspecto fundamental de la estrategia narrativa de Alcoba es que su punto de partida para narrar la vida clandestina, y el paso a la clandestinidad, es el énfasis en la cotidianidad. El relato de Laura comienza in median res respecto a la militancia, ya que ella está al tanto de la actividad de sus padres. A lo largo de la novela, la protagonista describe sus experiencias en base a una serie de rutinas: el viaje en colectivo a la casa de los abuelos, la ruta que recorre para ir a la escuela y la música que escucha, y más adelante sus juegos y actividades dentro de la casa donde se esconden. Estas rutinas son el sustrato del día a día. Cuando comienza el relato la protagonista goza de cierta calma, pero a medida que avanza la narración, se introduce una serie de elementos violentos y el acoso del terror estatal va creciendo. Inicialmente el peligro se presenta a cierta distancia, mediante la presencia de oficiales del gobierno que vigilan a la familia de Laura: una mujer que teje dentro de un auto estacionado cerca de la casa de los abuelos o la posibilidad de que alguien la siga cuando va al colegio. Eventualmente, Laura entra al mundo clandestino donde las personas deben asumir identidades falsas y aprender a ser otros. Ella va a una nueva escuela donde se ve obligada a mentir a sus maestros y compañeros, y en esta nueva circunstancia se esfuerza por comprender lo que ocurre a su alrededor y por desenvolverse de manera que no ocasione peligro a quienes la rodean. El hostigamiento crece y la foto de la madre de Laura aparece en los periódicos, por lo que ella ya no puede volver a ser vista en público. Así, llega un momento en que el acecho de las fuerzas represivas es tal que ya la madre de Laura no puede sostener su vida clandestina y, junto a su hija, huye del país. Sin embargo, a pesar de que el peligro crece, la novela no incluye episodios realmente violentos. La única excepción 
es una escena en que Didí le enseña a Laura cómo matar y cocinar los conejos que crían en la casa como fachada para ocultar la imprenta.

Nos interesa explorar la estrategia utilizada para describir este proceso teniendo en cuenta la dificultad de narrar estos eventos y la complejidad adicional que supone la voz narrativa infantil. Encontramos que la estrategia narrativa central que opera en el texto se basa en presentar lo irrepresentable mediante el prisma de lo cotidiano, es decir, que el acoso y el peligro se representan a través de las rupturas paulatinas y progresivas de lo habitual. La yuxtaposición entre el día a día previsible y los momentos en que ocurre un cambio, alude al peligro y sirve para darle énfasis. Se evita narrar la violencia que existe en el mundo exterior, la cual el lector puede inferir, enfocando en su lugar en las abruptas alteraciones de la rutina de la protagonista. Lo que ella percibe como natural, deja de serlo y poco a poco su día a día va cambiando: deja de visitar a los abuelos, abandona los viajes en colectivo, esconde su nombre verdadero, y tiene que comportarse de manera cautelosa. Cada uno de estos cambios viene a simbolizar el peligro implícito, que sólo existe en el entorno extraliterario histórico. El lector transpone su conocimiento de la dictadura a la lectura, y completa el sentido eludido. Así, la perspectiva infantil, no sólo tiene un valor testimonial sino que provee al autor de una estrategia narrativa que le permite circunvalar aquello que el lenguaje no puede decir, al tiempo que preserva la realidad histórica y comunica los sentimientos y emociones asociados a ella.

Otro aspecto interesante de este texto es el lenguaje. Sin embargo antes de continuar es esencial aclarar que el texto original de Alcoba fue escrito en francés, lengua en la cual se desenvolvió la autora después de su exilio, y en este análisis hemos referido a la excelente traducción hecha por Leopoldo Brizuela, la cual a nuestro parecer preserva todos los aspectos que discutimos a continuación. ${ }^{13}$ En La casa de los conejos se evidencia cómo el lenguaje no se da abasto para describir la situación de Laura. El caso más claro aparece alrededor de la palabra embute. La protagonista, ya adulta, recuerda haber oído este término durante la época en que vivió en la casa, pero años después ha olvidado su significado. Después de buscarlo en diccionarios y 
en internet, se da cuenta de que es un regionalismo obsoleto que fue usado por los militantes de aquella época; una huella de su experiencia. Aunque nunca lo define claramente, el lector entiende que se refiere a la imprenta clandestina y la fachada detrás de la cual se esconde. Embute ha caído en desuso, tanto en la región, como en el vocabulario de Laura. Es algo que sólo existe en el recuerdo y la experiencia compartida con quienes ya no pueden hablar. Así, adquiere un significado que no se puede esclarecer y funciona dentro del texto como un cronotopo que alude al pasado y a la pérdida. ${ }^{14}$

En un ejemplo paralelo, Laura formula un crucigrama a manera de juego con Didí. En él incluye las palabras: "Isabel", "Dar", "Muerte", "Arte", "Videla" y "Azar" (Alcoba, 2010, p. 88). Se llama la atención sobre esta última debido a que Laura la escribe con la letra "s" y Didí la corrige. ${ }^{15}$ "Asar/Azar" adquiere un significado especial ya que aparece en un momento cuando ya se plantea la huida de Laura y de su madre. La inferencia es que el éxito o fracaso de su escape es azaroso y que existe la posibilidad de que sean capturadas. Esta noción opera en un nivel pragmático cuando al lector hace una asociación al peligro que corren los personajes y el ejemplo demuestra claramente cómo la perspectiva narrativa infantil se entrecruza con la catástrofe del sentido descrita por Gatti para ilustrar el referente histórico de las novelas partir de nuevas estrategias narrativas. Cada una de las palabras usadas por Laura en el crucigrama actúa como un referente intertextual que completa el sentido de la narración.

A esto le sigue que el texto no presenta un desenlace claro. Son pocas las menciones al ataque a la casa de la Plata, quienes murieron allí y la desaparición de Clara Anahí Mariani. ${ }^{16}$ Un lector competente vinculará el personaje de Didí, aquella mujer embarazada que trata a la protagonista con tanto cariño, a la destinataria del prólogo. Esta breve epístola, no sólo enmarca la reflexión que realiza la autora sobre los eventos de su infancia sino que sirve como muestra del lazo afectivo que existió entre ellas.

Tal y como se presenta en la novela, durante la estadía de Laura en la casa clandestina, su madre estuvo dedicada por completo a la operación de la imprenta, desapareciendo durante el día detrás de la pared que 
la escondía. Didí toma su lugar. Está encargada de los quehaceres domésticos y tiene contacto constante con Laura. La interacción entre ellas es cariñosa y Didí adopta una actitud pseudo-maternal, que Laura acepta y hace recíproca. El ejemplo del crucigrama es uno de los fragmentos de la narración que tiene lugar en un espacio claramente doméstico donde Didí prepara la comida mientras que Laura hace las tareas:

A veces, Diana hace el papel de maestra para mí. Poco antes de empezar a preparar la cena, y de tender el mantel, platos y cubiertos, inventa algunos ejercicios que yo debo resolver sobre la mesa de la cocina. Casi siempre, son problemas matemáticos. (p.87)

Igualmente, ella llega a ocupar un rol pseudo-maternal en público. Ella y su esposo Cacho son un matrimonio modelo de jóvenes que esperan un hijo. Esta apariencia ayuda a proteger la casa de cualquier sospecha y coloca a Didí en un rol de intermediario con el mundo público. Como se ve en este ejemplo, donde alguien toca la puerta de manera inesperada, Didí modera las relaciones entre la niña y las personas que habitan fuera de la casa.

Por un momento, mi miedo fue más grande todavía. Me agarré de su vestido con las dos manos, escondiéndome entre sus piernas, caminando a su mismo ritmo. No sé si lo hice para estar más cerca de ella. ¿Hubiera querido quizá que me aferrara entre sus brazos? ¿O más aún, hubiera querido sobre todo acoplarme a su movimiento, fundirme en él al punto de desaparecer? [...]

- Se me ocurrió que la nena tendría ganas de venir un rato a casa. ¿Está?

Dando un paso al costado, salí de mi escondite. Había reconocido, sí, la voz de la vecina. Tan fresca como siempre. Siempre tan rubia.

- ¿Y? ¿Tenés ganas de venir conmigo un ratito?

Yo todavía era incapaz de decir palabra. Felizmente, Diana habló por mí.

- Claro que le gustaría. Eh, dale, ¿no es cierto que sí? (Alcoba, 2010, p.108-9) 


\section{Diana Pifano / María Soledad Paz-Mackay}

Didí amortigua el agudo contraste entre la vida clandestina y la vida pública. Vela por el bienestar de la niña y la conforta cuando siente miedo. Es lógico entonces que se establezca un vínculo pseudofamiliar entre ellas, y que desde su posición adulta la narradora sienta la obligación y el deseo de rendir homenaje a esa mujer que ocupó un papel central en aquella etapa tan difícil.

\section{(Re)formular la identidad desde la ausencia}

Hemos determinado que si bien en las novelas de los hijos de desaparecidos el evento traumático constituye un obstáculo desde el punto de vista narrativo, el mismo es el punto de partida para la formulación de la identidad. La vuelta a la infancia está al centro de la novela de Alcoba, y de muchas otras pertenecientes a este movimiento. Este posicionamiento del sujeto como voz narrativa que vuelve sobre el pasado actúa como marco narrativo y abre la puerta a las descripciones de las circunstancias del paso a la clandestinidad, la separación, la detención-desaparición y la vida de la segunda generación, las cuales son el sustrato a partir del cual los personajes como Laura se definen. Aún en los breves momentos en que se puede identificar su voz narrativa como adulta, la experiencia traumática es central. En La casa de los conejos esto se evidencia en el prólogo en que la autora se dirige a Diana Teruggi - no al personaje a quien luego llama Didí - para explicarle las circunstancias que la llevaron a escribir ese relato que ya hace mucho se había prometido contar. En ese caso la experiencia en la casa de los conejos se presenta como un evento que marca la vida de la narradora: "si al fin hago este esfuerzo de memoria para hablar de la Argentina de los Montoneros, de la dictadura y del terror, desde la altura de la niña que fui, no es tanto por recordar como por ver si consigo, al cabo, de una vez, olvidar un poco". (Alcoba, 2010, p.7)

El proceso de la toma de palabra y la reconstrucción del pasado comienzan por la experiencia compartida durante la dictadura y las consecuencias que esto ha aparejado para las víctimas y sus familias. La socióloga argentina Elizabeth Jelin (2003, p.15), expresa que la memoria tiene un rol fundamental por ser un proceso subjetivo que otorga significado al pasado, de acuerdo al momento en el cual se 
revisan las experiencias de los sujetos y los materiales que sirven a esa memoria. Por otro lado, Jelin y Kaufman entienden que dicho proceso subjetivo requiere de un "sujeto de la experiencia y de la palabra", por ello es necesario prestar atención a los "discursos que se construyen y se transmiten con el deseo de compartir, de legar, y de crear identidades y pertenencias" (2006, p.9). Tal es el caso de la novela en estudio, donde Laura plasma sus sentimientos de dolor, ausencia, nostalgia y culpa, los cuales sirven de pilar para reconstruir el universo narrativo de la vida clandestina, para perpetuar el recuerdo de sus seres queridos, y para alentar el diálogo sobre las consecuencias de los horrores de la dictadura. ${ }^{17}$

En la ficción en análisis, uno de los sentimientos omnipresentes es el miedo. Laura menciona en repetidas ocasiones que ella ha entendido la importancia de saber callar los secretos de adultos. Inclusive afirma “(d)el altillo secreto que hay en el cielorraso no voy a decir nada, prometido. Ni a los hombres que pueden venir y hacer preguntas, ni siquiera a los abuelos" (Alcoba, 2010, p.16). La protagonista sabe cuáles son los riesgos de hablar demasiado, y las posibles consecuencias para sus padres. Durante esa etapa de su infancia siente el acecho del peligro permanente en el que se encuentran. Explica que: "(y)o he comprendido y voy a obedecer. No voy a decir nada. Ni aunque vengan a casa y me hagan daño. $\mathrm{Ni}$ aunque me retuerzan el brazo o me quemen con la plancha" (Alcoba, 2010, p.18). Esta reconstrucción de su pasado en base a las referencias constantes al peligro que corren sus vidas, refuerza el valor y la madurez de la niña al centro del relato, dan cuenta de su participación en los eventos que narra y definen su identidad como hija de militantes Montoneros.

Como ya lo mencionamos, la estrategia central que permite abordar la tragedia y alrededor de la cual se forja la identidad de la narradora se basa en la mediación infantil de los eventos. La realidad exterior a la vida clandestina se representa mediante las alteraciones a la rutina de Laura, lo cual alude al contexto histórico. Por ejemplo, Laura afirma que todos le dicen que ella habla y razona como una persona mayor, a pesar de sus siete años, y agrega "(1)os hace reír que sepa el nombre de Firmenich, el jefe de los Montoneros..." (Alcoba, 2010, pp.17-8). 


\section{Diana Pifano / María Soledad Paz-Mackay}

La mención de su conocimiento de la conducción de la agrupación Montoneros, que junto a otros datos relevantes del funcionamiento de la imprenta clandestina o la distribución de los periódicos, implica un nivel de comprensión superior al de una niña pequeña. ${ }^{18}$ De manera similar, el lenguaje sirve para anclar el pasado perdido con el uso de palabras familiares o típicas de esa época. Un ejemplo se observa en el uso de embute, cuando tocan a la puerta en la casa donde vive Laura, y ve en el rostro de Diana el miedo que esto le produce. Laura "sabía que los militares podían llegar en cualquier momento, que las armas estaban en el embute precisamente por eso" (Alcoba, 2010, p.108).

Otro sentimiento importante en el proceso de la (re)construcción de la identidad de la protagonista es el afecto que siente por Diana. Esto se manifiesta desde la primera vez que la conoce en la nueva casa. Ella la describe a Didí como una persona hermosa, muy sonriente y que le transmite paz. Laura sostiene:

Puedo ver, sin embargo, que esa sonrisa pertenece al pasado, a algo que yo sé perdido para siempre. Pero como me reconforta, sea por lo que sea, ver que ella haya podido anclar en el tiempo para quedarse así, con ese rostro. (Alcoba, 2010, p.41).

Este es uno de los claros momentos en que la voz adulta de la narradora se infiltra en el relato sobre su pasado. Esta reflexión desde el presente es esencial en su construcción identitaria porque agrega una valoración. El recuerdo y la narración se vuelven uno en relación a la persona de Diana. Aunque el lector desconociera el desenlace en el cual Didí muere asesinada durante el tiroteo, esta reflexión adelanta lo inevitable. Asimismo, refleja que el afecto y respeto expresado por Laura hacia Didí es medular en el relato porque esa ausencia es una parte fundamental de su identidad.

A la dificultad que implica la presencia constante del miedo o la angustia del personaje central, se suma otro sentimiento al final del relato: la culpa que la protagonista siente por su partida. Laura lo menciona cuando relata las reuniones frecuentes que había en la casa para decidir este asunto. ${ }^{19}$ Allí escucha la propuesta de su madre a los compañeros sobre la posibilidad de denunciar lo que estaba pasando en 
Argentina desde Europa. Esto genera una situación incómoda y uno de los compañeros le contesta que muchos militantes se fueron, pero solo los dirigentes, la conducción. Ante el silencio perturbador que causa ese comentario, Laura reflexiona “ ¿(q)ué ha dicho? ¿Puede ser verdad? ¿Los militantes de base dan sus vidas mientras los jefes buscan refugio en el extranjero?" (p.120). Finalmente, después de varias reuniones toman la decisión de dejarlas partir de la casa, pero les avisan que no recibirán ayuda financiera ni auxilio, solo las van a cubrir mientras escapan. En ese momento, mientras Laura le ceba mate a César, uno de los miembros del grupo militante escucha que le dice a su madre: "(1) os nuestros mueren día a día. Nos están masacrando. Todavía podemos combatir..." (p. 121). La culpa por haber huido y haber sobrevivido la masacre en la que murió Didí y desapareció su hija forma parte de la reconstrucción del pasado de la protagonista y de la asunción de su identidad. Esta es la posición desde la cual ella le escribe la epístola correspondiente al prólogo. Laura comienza la escritura explicando que siente la necesidad de dar cuenta de lo que vivió, de honrar la memoria de la compañera que tanto quiso y de dialogar con ella en la única manera en que puede, pues esa es la forma en que le dará sentido a su situación de adulta y logrará conciliar el recuerdo con el entendimiento que ha logrado tantos años después.

Tal como hemos dicho, es imposible resumir o simplificar los elementos que componen la identidad (re)construida por los hijos de desaparecidos en sus novelas. Lo que queda claro es que ésta se construye en base a una herida abierta de la cual brotan sentimientos dolorosos, aun cuando se le examina desde el presente. Sin embargo, esta revisión contribuye al diálogo sobre el pasado de una nación y le da voz a la segunda generación de víctimas del régimen, que hasta hace poco permanecían en silencio.

\section{Conclusiones en torno a la identidad de los niños protagonistas}

Las páginas anteriores exploran las cualidades formales la novela en torno a la experiencia de la vida clandestina y la pérdida familiar ocasionada por el exilio. Nuestro análisis ha descrito las cualidades del texto a partir de las cuales se constituye la reflexión sobre el pasado, 
específicamente el papel de la voz narrativa infantil que emprende la difícil tarea de representar la cotidianidad de la vida clandestina en un contexto de angustia extrema. Se ha discutido también cómo el lenguaje sirve para anclar el pasado perdido e introducir referencias intertextuales que despiertan la memoria del lector, permitiendo que se diga lo indecible y se eluda lo indescriptible. Hemos descrito la relación entre la intención de recordar, y el proceso de reconstrucción de la memoria, el cual debe triunfar sobre el colapso del lenguaje y los sistemas de referencia tradicionales para arribar a una (re)formulación de la identidad de Laura: niña, protagonista, testigo, escritora, adulta, víctima.

En La casa de los conejos la construcción de la identidad de la protagonista se inicia desde su presente de adulta. Este anclaje temporal es necesario para abrir la puerta al proceso de la construcción del yo y la re-significación de ese pasado traumático. Mencionamos que recién después de 32 años de silencio, Laura comienza la recomposición de su identidad fracturada con el acto mismo de la narración. Al contar su historia del paso a la clandestinidad junto a su madre, vuelve a nombrar a sus seres queridos y sus sentimientos, y así se nombra a sí misma. El regreso a los eventos que comenzaron en 1975 y terminaron en su exilio es un ejercicio de memoria pero al mismo tiempo se convierte en una asunción de identidad. En ese cruce de discursos que existe entre los recuerdos reales de la casa de los conejos y las personas que la habitaron, y la ficción que Alcoba crea, se actualiza el nuevo sentido de su identidad como hija de militantes montoneros. A fin de cuentas, la suya es la formulación de una identidad tanto individual y privada como pública y colectiva que pertenece a una generación. El resultado es una novela de lectura simple y reflexión compleja que retoma el difícil pasado y negocia su interpretación contemporánea. 


\section{NOTAS}

1 En la novela, la imprenta clandestina estaba escondida en el patio trasero de una casa que tenía un criadero de conejos como fachada.

2 Traverso y Broderick definen el trauma desde una perspectiva psicológica como "a psychological injury produced by the experience of an external event that damages the individual's sense of self, and continues to produce belated negative effects".

3 Entre las obras escritas por hijos de desaparecidos se pueden mencionar dos novelas de Laura Alcoba, La casa de los conejos (2008) y Los pasajeros del Ana C (2012), Pequeños combatientes (2013) de Raquel Robles, Diario de una princesa montonera: 110\% verdad (2012) de Mariana Eva Pérez, 76 (2008) y Los topos (2008) de Félix Bruzzone, ¿Quién te crees que sos? (2012) de Ángela Urondo Raboy, y Soy un bravo piloto de la nueva China (2013) de Ernesto Semán, entre otras. Algunas de las ficciones de otros autores son: Lengua madre (2010) de María Teresa Andrueto, La casa operativa (2007) de Cristina Feijoo, El secreto y las voces (2007) y Un yuppie en la columna del Che Guevara (2011) de Carlos Gamerro, Una misma noche (2012) de Leopoldo Brizuela, Los planetas (1999) de Sergio Chejfec, Dos veces junio (2002), Museo de la revolución (2006) y Ciencias morales (2007) de Martín Kohan y también Kamchatka (2003) de Marcelo Figueras.

4 En esta categoría se encuentran: Recuerdo de la muerte de Miguel Bonasso (1984), La Voluntad: una historia de la militancia revolucionaria en la Argentina de Eduardo Anguita y Martín Caparrós (1997), Pájaros sin luz: testimonio de mujeres de desaparecidos de Noemí Ciolaro (1999), Ese infierno: conversaciones con cinco mujeres sobrevivientes de la ESMA (2001) y, por compartir un propósito afín podemos agregar a este grupo el informe Nunca más, publicado en 1984 por la Comisión Nacional sobre la Desaparición de Personas (CONADEP).

5 En Nombrar lo innombrable, Fernando Reati dedica un capítulo a analizar la relación entre memoria, novela e historia en la narrativa argentina. Allí, analiza primero algunas novelas de la "literatura de la dictadura", que se caracterizan —en su opinión — por desdibujar los límites entre lo imaginario y lo histórico. Se refiere a las novelas El mejor enemigo (1986) de Fernando López, De dioses, hombrecitos y policías (1975) de Humberto Constantini, La calle de los caballos muertos (1982) de Jorge Asís y Recuerdo de la muerte (1984) de Miguel Bonasso. Luego, se ocupa de otras 
novelas que se distinguen por dos tipos de desplazamiento: uno temporal, la novela histórica, y el otro de género, la novela policial.

6 Miguel Dalmaroni entiende que la confesión de Adolfo Scilingo, oficial de marina, marca un corte con la doxa previa del Nunca más, porque rompe con el mandato del secreto militar pero, además, porque "proponían una continuidad entre la subordinación de los uniformados a ordenes ilegales de sus superiores y el consentimiento de 'gran parte de la población'..." (2003, p.32).

7 Sus autores son herederos de los años en que el diálogo sobre la historia y la memoria se vio silenciado por las Leyes de Punto Final (1986) y Obediencia Debida (1987), y de la frustración sufrida por los familiares de las víctimas y las asociaciones de defensa de los derechos humanos, cuando a comienzos de los 90 el Presidente Carlos Menem otorgó indultos a los jefes militares y muchos otros que habían sido condenados previamente. Los autores en cuestión a menudo tienen vínculos personales con los movimientos de defensa de los derechos humanos, ya que muchos de ellos militaron y compartieron durante los primeros años de la asociación H.I.J.O.S (Hijos por la identidad y la justicia contra el olvido y el silencio), y tienen lazos con la Asociación de Abuelas de la Plaza de Mayo.

8 Este caso es singular porque la autora creció sin conocer su verdadera identidad. Fue adoptada ilegalmente por familiares maternos quienes le escondieron su pasado, incluyendo la militancia y la causa de la muerte de sus padres. Al enterarse, ya adulta, Urondo Raboy aborda la escritura con una perspectiva única entre los demás autores hijos. Es capaz de plantearse el proceso de la recuperación de su identidad en términos que carecen de toda dimensión infantil. Además, ella actúa como testigo en el juicio a los verdugos de sus padres, y da cuenta de ello en este texto. Gran parte de su relato trata sobre el juicio y las implicaciones personales que esa experiencia tuvo para la autora.

9 Un texto cuya temática es comparable es el filme Infancia clandestina de Benjamín Ávila. Este director realiza un proceso similar a Alcoba al entrelazar la ficción a los recuerdos personales de la vida clandestina que compartió con su madre y su hermano. Sin embargo, no incluiremos este filme en nuestro análisis debido a las diferencias que implica su formato audiovisual. 
10 Gatti ha publicado una bibliografía extensa sobre el tema, sin embargo la obra más representativa es Identidades desaparecidas. Peleas por el sentido en los mundos de la desaparición forzada (2001).

11 El autor recurre a dos tipos de narrativas para abordar la figura del detenido-desaparecido. La primera se construye en torno del concepto de lo invisible y explica que es útil para "las primeras fases de los procesos de restitución (...) cuando se reivindica la verdad y se reclama la visibilidad de algo" (2003, p.28), esta noción corresponde a lo que hemos denominado la primera generación de textos sobre el tema. Organiza el segundo tipo alrededor del concepto de vacío, el cual aparece "en momentos sensibles a mayores dosis de complejidad" (2003, p.28) y este es el caso de los textos que consideramos aquí, aquellos que se distancian del momento histórico que describen y del proceso socio-político que le siguió. Para el sociólogo uruguayo ambas categorías comparten un mismo sentido temático puesto que señalan aquello que existe pero no se ve y es imposible de representar.

12 Fernando Reati también aborda esta noción al describir la novela El lago (2005) de Paola Kaufmann, la cual aborda el tema de los detenido-desaparecidos que fueron echados a las aguas. Reati dice:

La novela recurre a la alegoría para resolver el dilema central en todo intento de representación del horror: ¿cómo describir aquello que por su naturaleza misma es irrepresentable? En el caso argentino lo que no se puede representar es la desaparición de personas, y los diversos calificativos de Ana [protagonista de la novela] para designar al animal nunca visto aluden a esa incapacidad de describir por otros medios que no sean la alusión, la tangencialidad o en última instancia la alegoría. (2012, p.302)

13 Usamos la 1era edición de la novela traducida por Brizuela. Cabe mencionar que el traductor es también autor de una novela sobre el terrorismo de estado: Una misma noche (2012). Asimismo, Brizuela ha traducido la última novela de Alcoba, El azul de las abejas (2014), escrita originariamente en francés como sus novelas anteriores.

14 Utilizamos el término cronotopo siguiendo la definición de Mikhail Bakhtin (1895-1975) "We will give the name chronotope (literally, "time space") to the intrinsic connectedness of temporal and spatial relationships that are artistically expressed in literature" (84).

15 Esta circunstancia en particular del error ortográfico nos remite a la novela Dos veces junio (2002) de Martín Kohan, la cual comienza con la pregunta 


\section{Diana Pifano / María Soledad Paz-Mackay}

escrita en un cuaderno de notas por un dependiente militar de bajo rango "a que edad es posible empesar (sic) a torturar a un niño? (...)

16 La primera mención ocurre en el prólogo. Luego se dice que al acabar la dictadura el padre de Laura, quien estuvo preso durante los años del régimen, le dio un libro, Los del '73 donde se menciona lo ocurrido en el ataque a esa casa. En otra ocasión, Laura conversa con la madre de Daniel Mariani, el esposo de Diana Teruggi quien es representado por el personaje de Cacho. Finalmente, en las últimas líneas de la novela se dirige de nuevo a Diana para decirle:

Clara Anahí vive en alguna parte. Ella lleva sin duda otro nombre. Ignora probablemente quiénes fueron sus padres y cómo murieron . Pero estoy segura, Diana, que tiene tu sonrisa luminosa, tu fuerza y tu belleza.

Eso, también, es una evidencia excesiva. Paris, marzo de 2006. (Alcoba, 2010, p.134)

17 Se ha discutido extensamente en el ámbito académico sobre si este tipo de memoria puede ser calificada como postmemoria o no, en particular por la implicación subjetiva del sujeto. Marianne Hirsch al referirse a la postmemoria explica: "I see it, (...) as a structure of inter- and transgenerational transmission of traumatic knowledge and experience. It is a consequence of traumatic recall but (unlike post-traumatic disorder) at a generational remove" (2008: 106). Nos interesan las ideas de Hirsch en tanto observamos una nueva variante de memoria, basada en la escritura. Para Hirsch “[p]ostmemory's connection to the past is thus not actually mediated by recall but by imaginative investment, projection, and creation" (2008: 107). La escritura es una creación, una manera de volver a ese pasado y darle sentido, ficcionalmente o como autoficciones.

18 Otro ejemplo que ilustra esta idea es cuando Laura expresa “(e)l ingeniero ha venido a ver si todo marcha bien. Sentado junto a mí, hace girar las perillas del control que pone en funcionamiento el mecanismo del embute" (Alcoba, 2010, p. 99).

19 La protagonista escucha las conversaciones sobre su partida al extranjero, posibilidad introducida por el abuelo materno, mientras ceba mate. Ella afirma: "siempre en silencio, pero no me pierdo una sola palabra de la conversación..." (120). 


\section{Referencias bibliográficas}

Alcoba, L. (2010). La casa de los conejos. Buenos Aires: Edhasa.

Arfuch, L. (ed.). (2005). Identidades, sujetos y subjetividades. Buenos Aires: Prometeo Libros.

Avellaneda, A. (1997). Lecturas de la historia y lecturas de la literatura en la narrativa argentina de la década del ochenta. En Memoria colectiva y políticas de olvido Argentina y Uruguay, 1970-1990. A. Bergero \& F. Reati (ed .). Buenos Aires: Beatriz Viterbo.

Avellaneda, A. (1995). Hablar y callar. Construyendo sentido en la democracia. En Hispamérica 72: pp. 27-38.

Blejmar, J. \& Fortuny, N. Introduction. En Journal of Romance Studies. 13(3): 1-5. Recuperado de: http://www.academia.edu/10516214/ Introduction_Journal_of_Romance_Studies_Volume_13_Issue_3_.

Dalmaroni, M. (2003). La moral de la historia: novelas argentinas sobre la dictadura. En Hispamérica 32.96: pp. 29-47

Doubrovsky, S. (1977). Fils. Paris: Galilée.

Gatti, G. (2006). Las narrativas del detenido-desaparecido (o de los problemas de la representación ante las catástrofes sociales). En CONfines 4: pp. 27-38.

Gramuglio, María Teresa. (2002). Políticas del decir y formas de la ficción. Novelas de la

dictadura militar. En Punto de vista 74: 9-14.

Hirsch, Marianne. (2008). The Generation of Postmemory. En Poetics Today 19 (1) 103-128.

Jelin, Elizabeth. (2003). State Repression and the Labours of Memory. Minnesota:

University of Minnesota Press.

Jelin, E. \& Kaufman S. (ed.). (2006). Subjetividad y figuras de la memoria. Buenos Aires: Siglo XXI.

Kirchner, N. (2003). Discurso inaugural. Recuperado de

http://www.casarosada.gob.ar/discursosnk/24414-blank-18980869.

Reatti, F. (1992) Nombrar lo innombrable: violencia política y novela argentina. 1975-1985. Buenos Aires: Editorial Legasa.

Kohan, M. (2002) Dos veces junio. Buenos Aires: Sudamericana.

Gatti, G. (2001). Identidades desaparecidas. Peleas por el sentido en los mundos de la desaparición forzada. Buenos Aires: Prometeo Libros.

Robles, R. (2013) Pequeños combatientes. Buenos Aires: Alfaguara.

Sarlo, B. (1993) Literatura y política. En Punto de vista 19: 8-11

Trauma Studies. En Continum. Journal of Media and cultural Studies. 24 (1): 3-15. Web. 30 Jun. 2015. Recuperado de: 


\section{Diana Pifano / María Soledad Paz-MackaY}

http://novanetprimo.hosted.exlibrisgroup.com/DAL:default_scope:TN_ tayfranc10.1080/10304310903461270

Vezzetti, H. (2002). Pasado y presente. Guerra, dictadura y sociedad en la Argentina. Buenos Aires: Siglo XXI Editores Argentina.

Urondo Raboy, A. (2013) ¿Quién te crees que soy? Buenos Aires. 